\title{
Molecular entrapment of volatile organic compounds (VOCs) by electrospun cyclodextrin nanofibers
}

\author{
Asli Celebioglua ${ }^{a, b}$, Huseyin Sener Sen ${ }^{b}$, Engin Durgun ${ }^{a, b}$, Tamer Uyar ${ }^{a, b, *}$ \\ a Institute of Materials Science \& Nanotechnology, Bilkent University, Ankara, 06800, Turkey \\ ${ }^{\mathrm{b}}$ UNAM-National Nanotechnology Research Center, Bilkent University, Ankara, 06800, Turkey
}

\section{H I G H L I G H T S}

- Polymer-free $\mathrm{HP} \beta \mathrm{CD}$ and $\mathrm{HP} \gamma \mathrm{CD}$ nanofibers were obtained via electrospinning.

- Molecular entrapment performance of $\mathrm{CD}$ nanofibers and powders was investigated.

- Volatile organic compounds (VOCs; aniline, benzene) were used for entrapment test.

- CD nanofibers can entrap higher amount of VOCs compared to their powder forms.

- $\mathrm{CD}$, solvent and VOCs types are the other elements effect encapsulation efficiency.

\section{A R T I C L E I N F O}

\section{Article history:}

Received 13 March 2015

Received in revised form 21 July 2015

Accepted 6 September 2015

Available online 25 September 2015

Handling editor: Jun Huang

Keywords:

Cyclodextrin

Electrospinning

Nanofibers

Volatile organic compounds

Molecular filtration
G R A P H I C A L A B S T R A C T

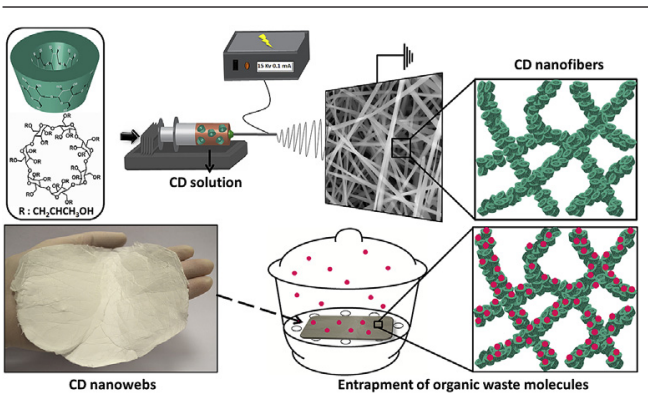

\begin{abstract}
A B S T R A C T
In this paper, we reported the molecular entrapment performance of hydroxypropyl-beta-cyclodextrin ( $\mathrm{HP} \beta \mathrm{CD}$ ) and hydroxypropyl-gamma-cyclodextrin (HP $\gamma \mathrm{CD}$ ) electrospun nanofibers (NF) for two common volatile organic compounds (VOCs); aniline and benzene. The encapsulation efficiency of CD samples were investigated depending on the various factors such as; $C D$ form (NF and powder), electrospinning solvent (DMF and water), CD (HP $\beta C D$ and $\mathrm{HP} \gamma \mathrm{CD}$ ) and VOCs (aniline and benzene) types. BET analysis indicated that, electrospun CD NF have higher surface area compared to their powder form. In addition DMA measurement provided information about the mechanical properties of CD NF. The encapsulation capability of $\mathrm{CD} N \mathrm{NF}$ and $\mathrm{CD}$ powder was investigated by ${ }^{1} \mathrm{H}-\mathrm{NMR}$ and HPLC techniques. The observed results suggested that, CD NF can entrap higher amount of VOCs from surroundings compared to their powder forms. Besides, molecular entrapment efficiency of CD NF also depends on $C D$, solvent and VOCs types. The inclusion complexation between $\mathrm{CD}$ and VOCs was determined by using TGA technique, from the higher decomposition temperature of VOCs. Finally, our results were fortified by the modeling studies which indicated the complexation efficiency variations between $C D$ and VOC types. Here, the inclusion complexation ability of $\mathrm{CD}$ molecules was combined with very high surface area and versatile features of CD NF. So these findings revealed that, electrospun CD NF can serve as useful filtering material for air filtration purposes due to their molecular entrapment capability of VOCs.
\end{abstract}

(c) 2015 Elsevier Ltd. All rights reserved.

\footnotetext{
* Corresponding author. Institute of Materials Science \& Nanotechnology, Bilkent University, Ankara, 06800, Turkey.

E-mail address: tamer@unam.bilkent.edu.tr (T. Uyar).
} 


\section{Introduction}

Volatile organic compounds (VOCs) are a wide group of organic molecules that are considered as one of the major sources of air pollution. VOCs are significantly emitted into air from industrial plants, vehicles, aircraft, perfumes, etc (De Crom et al., 2010; Irusta et al., 1998) VOCs are well known with their highly toxic and carcinogenic features; therefore they can cause harmful impacts on human health and ecosystem. So it is essential to decrease the negative effect of VOCs by removing them from the environment (Esteve-Turrillas et al., 2007; Meniconi et al., 2003). The absorption/adsorption are considered as an efficient way for the removal of VOCs from air. Active carbon is the commonly used material to reduce the VOCs degree in the surrounding due to its high surface area and porous structure (Bradley and Rand, 1995; Bradley et al., 2011; Majumdar et al., 2001; Vermisoglou et al., 2007). However, the carbon based absorbents/adsorbents are generally applied in the powder or granular form and this creates challenges during their use in terms of handling and reusability (Scholten et al., 2011). For this reason, there are approaches in the literature including the formation of flexible nano-scaled matrix which were obtained with the incorporation of electrospinning technique (Bai et al., 2013a, 2013b; Katepalli et al., 2011; Kim et al., 2013; Lee et al., 2010; Scholten et al., 2011).

Over the past decade, the production of nanofibers (NF) is particularly concentrated on the electrospinning due to simplicity of this technique and it is versatile and cost-effective. In this technique, it is quite applicable to fabricate NF from various kinds of polymers, polymer blends, sol-gels and composites (Greiner and Wendorff, 2007; Ramakrishna et al., 2005; Wendorff et al., 2012). The NF obtained by electrospinning exhibit unique properties such as; small pore sizes, high pore density, large surface-to-volume ratio and design flexibility for particular physical and chemical functionalization (Aussawasathien et al., 2008; Greiner and Wendorff, 2007; Li and Xia, 2004; Pant et al., 2013; Ramakrishna et al., 2005, 2006; Wendorff et al., 2012). Owing to their remarkable properties, electrospun NF and their nanowebs are especially promising candidates to be used in membranes/filters and environmental applications (Aluigi et al., 2014; Aussawasathien et al., 2008; Pant et al., 2013; Uyar et al., 2010a; Wang et al., 2013; Xie et al., 2008; Yoon et al., 2008; Pant et al., 2014). Moreover, these nanowebs can naturally overclass the powder type of absorbents/adsorbent, since it is simultaneously possible to provide molecular encapsulation and particle capturing during the filtration process by using electrospun NF. Besides, the effect of secondary pollution might be reduced along with the reusability and regeneration of these nanowebs. From this point of view, there are studies in the literature reporting that, the electrospun NF were experienced as membrane system for VOCs filtration purposes. For instance, Scholten et al. firstly used the electrospun polyurethane fibers for the removal of VOCs (Scholten et al., 2011). In another related study, reduced graphene oxide (RGO)/carbon composite ultrafine fibers were developed by using electrospinning and applying consequent carbonization to evaluate their VOCs adsorption performance (Bai et al., 2013a). One of the associated studies, the fly ash particles were blended with polyurethane to produce composite electrospun membranes for the removal of VOCs (Kim et al., 2013). In our very recent reports, we functionalized electrospun poly (methyl methacrylate) (PMMA) NF with $\beta$-cyclodextrin ( $\beta$-CD) molecules (Uyar et al., 2010b). In another study, we functionalized electrospun polyethylene terephthalate (PET) NF with three native CD types $(\alpha-C D, \beta-C D$ and $\gamma-C D)$ for the entrapment of VOCs from environment (Kayaci and Uyar, 2014).

Cyclodextrins (CD) are cyclic oligosaccharides which are pro- duced from the enzymatic conversion of starch and known with its toroid-shaped molecular structure. Owing to this intriguing supramolecular mould, CD can form non-covalent host-guest inclusion complexes (IC) with a variety of molecules so they are particularly applicable in various field such as pharmaceuticals, functional foods, cosmetics, home/personal care, textiles etc (Blach et al., 2008; Flaherty et al., 2013; Harada et al., 2011; Hedges, 1998; Shao et al., 2010; Szejtli, 1998). Some molecules that CD form IC can be hazardous and polluting chemicals, so CDs are fairly useful for filtration/separation/purification areas (Olah et al., 1988; Crini and Morcellet, 2002; Landy et al., 2012; Morin-Crini and Crini, 2013; Schofield et al., 2012). For this purpose, it can be considered that, $\mathrm{CD}$ have also potential for the elimination of VOCs from the environment (Favier et al., 2011; Mauri-Aucejo et al., 2012). However, during the use of powder and cross-linked polymeric granular form of $C D$, handling and reusability appear as challenge which restricts their potential. So, as an alternative approach we employed electrospinning technique in order to produce NF from CD molecules only (Celebioglu and Uyar, 2010, 2012, 2013a, 2013b). We obtained CD NF from three different chemically modified $\mathrm{CD}$ (hydroxypropyl-beta-cyclodextrin (HP $\beta C D$ ), hydroxypropyl-gamma-cyclodextrin (HP $\gamma \mathrm{CD}$ ) and methyl-betacyclodextrin $(\mathrm{M} \beta \mathrm{CD}))$ and three native $\mathrm{CD}(\alpha-\mathrm{CD}, \beta-\mathrm{CD}$ and $\gamma$ $\mathrm{CD}$ ). Consequently, the ultimate NF are more applicable compared to powder form of $\mathrm{CD}$ and these NF can be especially attractive for the filtration applications by combining high surface area of NF with the complexation property of $\mathrm{CD}$. As a preliminary study, we have evaluated the molecular filtration potential of electrospun $\gamma$ $\mathrm{CD} \mathrm{NF}$ by entrapping of aniline and toluene from the surrounding owing to inclusion complexation (Celebioglu and Uyar, 2013b).

In the present study, we have investigated the molecular filtration capability of electrospun HP $\beta$ CD NF and HP $\gamma$ CD NF by entrapping VOCs (aniline and benzene) from the surrounding. For this purpose, $\mathrm{HP} \beta \mathrm{CD} \mathrm{NF}$ and $\mathrm{HP} \gamma \mathrm{CD}$ NF were electrospun from two different solvent systems (water and DMF) and these NF were exposed to vapor of aniline and benzene. For comparison, the entrapment test was also performed for the powder form of $\mathrm{HP} \beta C D$ and $\mathrm{HP} \gamma \mathrm{CD}$. The morphological characteristics of the $\mathrm{HP} \beta \mathrm{CD} \mathrm{NF}$ and $\mathrm{HP} \gamma \mathrm{CD}$ NF before and after the entrapment of VOCs and asreceived powder were examined by scanning electron microscopy (SEM). Brunauer-Emmett-Teller (BET) surface area analyzer was used to measure the surface area of $\mathrm{HP} \beta C D$ and $\mathrm{HP} \gamma \mathrm{CD}$ in powder form and NF form. Moreover, dynamic mechanical analyzer (DMA) was employed for the investigation of the mechanical properties of these nanowebs. After exposing to VOCs vapor, the entrapped amount of VOCs by CD NF and their powder were investigated by using proton nuclear magnetic resonance $\left({ }^{1} \mathrm{H}\right.$ NMR) and high performance liquid chromatography (HPLC) techniques. In addition, thermal gravimetric analyzer (TGA) was used to prove the inclusion complexation between CD and VOCs during the encapsulation. Finally, modeling studies were performed to understand the complexation efficiency variations between CD and VOC types in terms of complexation energy.

\section{Materials and methods}

\subsection{Materials}

Hydroxypropyl-beta-cyclodextrin ((HP $\beta \mathrm{CD})$, molar substitution:0.6) and hydroxypropyl-gamma-cyclodextrin ((HP $\gamma \mathrm{CD})$, molar substitution:0.6) were obtained from Wacker Chemie AG, Germany commercially. N,N-Dimethylformamide (DMF) (Rie-del, Pestenal), aniline (Sigma-Aldrich, 99\%), benzene (Sigma-Aldrich, 99.8\%), acetonitrile (Chromasolv, HPLC $\geq 99.9 \%$ ) and d6-DMSO (Merck) were 
purched. The deionized water was supplied from the Millipore Milli-Q Ultrapure Water System. All the materials were used without any purification.

\subsection{Electrospinning of $C D$ nanofibers (NF)}

The optimization of modified CD (HP $\beta$ CD and $\mathrm{HP} \gamma \mathrm{CD}$ ) NF was reported in our previous study (Celebioglu and Uyar, 2012). Here, the homogenous solutions of modified CD were prepared in water and DMF at the predetermined concentration for the electrospinning of uniform, bead-free NF. Thereafter, the clear CD solutions were filled into $3 \mathrm{ml}$ syringes (metallic needle with 0.45 inner diameter) and positioned horizontally on the syringe pump (Model: SP 101IZ, WPI). The electrodes of high voltage power supply (Matsusada Precision, AU Series) were clamped to the grounded cylindrical aluminum collector and the metal needle tip of syringe. The parameter of electrospinning was determined as following: applied voltage $=15 \mathrm{kV}$, tip-to-collector distance $=15 \mathrm{~cm}$ and the solution flow rate $=0.5 \mathrm{ml} / \mathrm{h}$. The electrospinning was carried out in the enclosed Plexiglas box at $23{ }^{\circ} \mathrm{C}$ at $25 \%$ relative humidity and the electrospun CD NF were deposited on a grounded stationary cylindrical metal collector covered by a piece of aluminum foil. The collected CD NF were dried at $90{ }^{\circ} \mathrm{C}$ in the vacuum oven overnight in order to remove the existent residual solvent.

\subsection{Characterizations and measurements}

\subsubsection{Scanning electron microscopy (SEM), Brunauer-Emmett-Teller} (BET) and dynamic mechanical analyzer (DMA)

The morphologies of CD NF before/after filtration test and CD powder were investigated by using SEM (Quanta 200 FEG, FEI). The average fiber diameters (AFDs) and their distributions were calculated by analyzing around 100 fibers from the SEM images. The samples were coated with $5 \mathrm{~nm} \mathrm{Au/Pd}$ before the SEM imaging (PECS-682). BET surface area analyzer (Quantachrome, IQ-C model) was used to calculate the surface area of powder and NF. Nitrogen adsorption isotherm data were collected at $77 \mathrm{~K}$ in the range of $0.00-1.00$ relative pressure. Prior to analysis, powder and NF were located into $9 \mathrm{~mm}$ cell and degassed for $12 \mathrm{~h}$ at $373 \mathrm{~K}$. Tensile tests were carried out by using DMA (Q800 TA Instruments) equipped with tensile fixture. The stress/strain curves of rectangular shaped samples were obtained at $0.25 \mathrm{~N} / \mathrm{min}$ force ramp and the average values were calculated by performing three measurements. For each sample, the gap between jaws was kept at $7 \mathrm{~mm}$ and the responses were gotten at room temperature.

\subsubsection{Entrapment of VOCs by $C D N F$ and their powder}

The molecular filtration performance of $\mathrm{CD} N \mathrm{NF}$ was evaluated by trapping VOCs (aniline and benzene) vapors. For this experiment, $10 \mathrm{ml}$ of aniline or benzene were put into glass Petri dishes and located at the bottom of the desiccator (30 cm (diameter) and $30 \mathrm{~cm}$ (height)). As well, the $100 \mathrm{mg} \mathrm{CD} \mathrm{NF}$ produced from $\mathrm{HP} \beta \mathrm{CD}$ and $\mathrm{HP} \gamma \mathrm{CD}$ in water and DMF, beside their as-received powder were placed into the sealed desiccator. Samples were exposed aniline and benzene atmosphere for $12 \mathrm{~h}$, afterwards, they were taken out of the desiccators and kept into suction hood for $1 \mathrm{~h}$ to remove the solvent molecules that were just adsorbed and could not form inclusion complex (IC) with CD molecules. The examination of the encapsulated amount was carried out by proton magnetic resonance $\left({ }^{1} \mathrm{H}\right.$ NMR) and high performance liquid chromatography (HPLC). Thermal gravimetric analyzer (TGA) was used to demonstrate the thermal shifts of aniline and benzene degradation/evaporation due to the IC formation during the filtration.

\subsubsection{Proton nuclear magnetic resonance $\left({ }^{1} \mathrm{H}-\mathrm{NMR}\right)$}

The entrapped amount of VOCs was firstly analyzed by using ${ }^{1} \mathrm{H}-\mathrm{NMR}$ (Bruker D PX-400) system. The samples were dissolved in d6-DMSO for both aniline and benzene experiments at the $20 \mathrm{~g} / \mathrm{L}$ concentration. The spectra were recorded at $400 \mathrm{MHz}$ and at 16 total scan. The molar ratios between organic molecules to $\mathrm{CD}$ (VOCs:CD) were determined by integrating the peak ratio of the characteristic chemical shifts $(\delta)$ corresponding to $C D$, aniline and benzene by using NMR software. The particular peaks belong to aniline and benzene were observed at the aromatic region of NMR spectrum (6.7 and $7.1 \mathrm{ppm}$ for aniline, $7.3 \mathrm{ppm}$ for benzene). The molar ratios were calculated by taking account the integration of aniline, benzene aromatic peaks and the CD's characteristic peak at about $1.0 \mathrm{ppm}\left(\mathrm{CH}_{3}\right.$ of -hydroxypropyl group) for d6-DMSO system. The measurements were repeated three times for each sample.

\subsubsection{High performance liquid chromatography (HPLC)}

The filtration capability of samples was also supported by using HPLC system (Agilent 1200 Series). Before the measurements, aniline and benzene exposed $\mathrm{CD} N \mathrm{NF}$ and powder were dissolved in an appropriate solvent system for the detection of VOCs encapsulated in the $\mathrm{CD}$ molecules. While the aniline treated NF and powder ( $5 \mathrm{mg}$ ) were dissolved in water $(1 \mathrm{ml})$, the benzene treated NF and powder were prepared in water/acetonitrile $(\mathrm{ACN})(7 / 3)(1 \mathrm{ml})$ blend system. The measurements were repeated three times for aniline and benzene exposed samples. The separation of both aniline and benzene were achieved by using Zorbax Eclipse XDB-C18 column (150 mm $\times 4.6 \mathrm{~mm}, 5 \mu \mathrm{m}$ particle sizes) and they were detected at $200 \mathrm{~nm}$ and $254 \mathrm{~nm}$ wavelengths, respectively. For aniline experiment, water/ACN (50/50) (v/v) was used as mobile phase at a flow rate of $0.75 \mathrm{ml} / \mathrm{min}$ and the injection volume was kept at $5 \mu \mathrm{l}$. The calibration curve of aniline was prepared from $600 \mathrm{ppm}$ to $10 \mathrm{ppm}$ concentrations by diluting each aniline solution and it showed linearity and acceptability with $\mathrm{R}^{2} \geq 0.99$. For benzene experiment, water/ACN (25/75) (v/v) was used as mobile phase at a flow rate of $0.75 \mathrm{ml} / \mathrm{min}$ and the injection volume was kept at $20 \mu \mathrm{l}$. The calibration curve of benzene was prepared from $200 \mathrm{ppm}$ to $0.002 \mathrm{ppm}$ concentrations by diluting each benzene solution and it showed linearity and acceptability with $R^{2} \geq 0.99$. All measurement results were adapted to their calibration curves in terms of peak area under curves.

\subsubsection{Thermal gravimetric analyzer (TGA)}

TGA (Q500, TA Instruments) was performed to demonstrate the thermal shifts of aniline and benzene that is originated from the inclusion complexation between $\mathrm{CD}$ and organic molecules. The TGA of the samples was carried out from 25 to $500{ }^{\circ} \mathrm{C}$ at $20^{\circ} \mathrm{C} / \mathrm{min}$ heating rate and $\mathrm{N}_{2}$ was used as a purge gas.

\subsection{Computational method}

The first-principles techniques based on density functional theory (Hohenberg and Kohn, 1964; Kohn and Sham, 1965) were used to model CD, VOCs, and their IC. The temperature effects are excluded in the ground state calculations. The initial geometries of $\beta$-CD (Lindner and Saenger, 1982) and $\gamma$-CD (Harata, 1987) were obtained from Cambridge Structural Database (Allen, 2002). The chemically modified $C D(H P \beta C D$ and $H P \gamma C D)$ are modeled by manually adding 2-hydroxypropyl groups on the primary groups of native $\beta$-CD and $\gamma-\mathrm{CD}$ with a substitution degree per (anhydro) glucose unit of 0.6. The exchange-correlation interactions were treated within generalized gradient approximation (GGA-PBE) (Perdew et al., 1992) with inclusion of Van der Waals correction (Grimme, 2006) implemented in the Vienna $A b$ initio simulation package (Kresse and Furthmüller, 1996a, 1996b). 
The element potentials were described by projector augmentedwave method (PAW) (Blöchl, 1994) using a plane-wave basis set with a kinetic energy cutoff of $400 \mathrm{eV}$. All structures were optimized using the blocked-Davidson algorithm with simultaneous minimization of the total energy and interatomic forces. The convergence on the total energy and force was tested and then set to $10^{-5} \mathrm{eV}\left(10^{-4} \mathrm{kcal} / \mathrm{mol}\right)$ and $10^{-2} \mathrm{eV} / \mathrm{A}\left(10^{-2} \mathrm{nN}\right)$, respectively.

\section{Results and discussion}

\subsection{Structural characterization of cyclodextrin (CD) nanofibers (NF)}

The electrospinning parameters for producing uniform NF from $\mathrm{HP} \beta \mathrm{CD}$ and $\mathrm{HP} \gamma \mathrm{CD}$ by using water and DMF as solvent were reported in our previous study (Celebioglu and Uyar, 2012). The schematic representation of the $\mathrm{HP} \beta C D$ molecules and the electrospinning of $\mathrm{HP} \beta \mathrm{CD} \mathrm{NF}$ were given in Fig. 1a-b. The representative scanning electron microscopy (SEM) images of $\mathrm{HP} \beta \mathrm{CD}$ and $\mathrm{HP} \gamma \mathrm{CD}$ powder, $\mathrm{HP} \beta \mathrm{CD}$ and $\mathrm{HP} \gamma \mathrm{CD}$ NF obtained from water and DMF at the required level of concentration for the production of bead-free electrospun NF are illustrated in Fig. 2. The $\mathrm{SEM}$ images of $\mathrm{HP} \beta \mathrm{CD} /$ powder and $\mathrm{HP} \gamma \mathrm{CD} /$ powder are given in Fig. 2(a-i)-(b-i) and as it is observed, both of them have spherical morphology with wider range of size distribution compared to $\mathrm{HP} \beta \mathrm{CD}$ and $\mathrm{HP} \gamma \mathrm{CD}$ NF. The uniform $\mathrm{HP} \beta \mathrm{CD}$ NF were obtained at $160 \%(w / v)$ for water (Fig. $2(a-i i))$ and at $120 \%(w / v)$ for DMF (Fig. 2(a-iii)). On the other hand, the bead-free HP $\gamma$ CD NF were produced at $160 \%(\mathrm{w} / \mathrm{v})$ for water (Fig. 2(b-ii)) and at $125 \%(\mathrm{w} / \mathrm{v})$ for DMF (Fig. 2(b-iii)) (Table 1). While the average fiber diameter (AFDs) of $\mathrm{HP} \beta \mathrm{CD} /$ water-NF and $\mathrm{HP} \beta \mathrm{CD} / \mathrm{DMF}-\mathrm{NF}$ were determined as $745 \pm 370 \mathrm{~nm}$ and $1125 \pm 360 \mathrm{~nm}$ respectively, they were calculated as $1165 \pm 455 \mathrm{~nm}$ for $\mathrm{HP} \gamma \mathrm{CD} /$ water-NF and $2740 \pm 725 \mathrm{~nm}$ for $\mathrm{HP} \gamma \mathrm{CD} / \mathrm{DMF}-\mathrm{NF}$ (Table 1). The fiber diameter distributions are given in Fig.S1 in the supporting information. Both of $\mathrm{HP} \beta \mathrm{CD} \mathrm{NF}$ and $\mathrm{HP} \gamma \mathrm{CD}$ NF have thicker diameter for DMF system when compared to water system. As explained in detail in our previous study (Celebioglu and Uyar, 2012), uniform CD NF were obtained at lower concentration in DMF contrary to water system, in addition, $\mathrm{HP} \gamma \mathrm{CD}$ NF have thicker diameter compared to $\mathrm{HP} \beta \mathrm{CD}$ NF. HP $\gamma \mathrm{CD}$ solutions have higher viscosity and lower conductivity so its electrified jet is exposed to less stretching during electrospinning and yields thicker fibers compared to $\mathrm{HP} \beta \mathrm{CD}$ solutions (Celebioglu and Uyar, 2012; Uyar and Besenbacher, 2008; Ramakrishna et al., 2005).

The mechanical property of the $C D$ nanowebs was investigated visually in the previous study (Celebioglu and Uyar, 2012). It was expected that, $C D$ nanowebs can be very weak and brittle because of the amorphous structure and full existence of small CD molecules. However, it was observed that, CD nanowebs have shown some mechanical strength and flexibility which they can be easily folded and handled, except for $\mathrm{HP} \gamma \mathrm{CD} / \mathrm{DMF}-\mathrm{NF}$ (Celebioglu and Uyar, 2012). To this respect, we have decided to investigate the application potential of these novel NF for the filtration purposes. Here, we have also put the representative photograph of $\mathrm{HP} \beta \mathrm{CD} \mathrm{NF}$ as an example to show the mechanical integrity and flexible nature of $C D$ nanowebs (Fig. 1c). In our previous study, we did not use dynamic mechanical analyzer (DMA) technique to determine the mechanical property of these nanowebs, on the other hand, here we have carried out this measurement to get more information in this regard. For $\mathrm{HP} \gamma \mathrm{CD} / \mathrm{DMF}-\mathrm{NF}$, we could not able to perform mechanical test, because these nanowebs have more brittle structure and it was not easy to handle it when compared to $\mathrm{CD}$ nanowebs of $\mathrm{HP} \beta \mathrm{CD} /$ water-NF, $\mathrm{HP} \beta \mathrm{CD} / \mathrm{DMF}-\mathrm{NF}$ and $\mathrm{HP} \gamma \mathrm{CD} /$ water-NF. Table S1 summarized the mechanical properties of $\mathrm{HP} \beta \mathrm{CD} /$ water-NF, $\mathrm{HP} \beta \mathrm{CD} / \mathrm{DMF}-\mathrm{NF}$ and $\mathrm{HP} \gamma \mathrm{CD} /$ water$\mathrm{NF}$ which were attained from the stress-strain curve. We observed that, the ultimate tensile strength and the young modulus of $\mathrm{HP} \beta \mathrm{CD} /$ water-NF are significantly higher compared the $\mathrm{HP} \beta \mathrm{CD} / \mathrm{DMF}-\mathrm{NF}$ (Table S1). The reason for this situation is possibly due to the thicker fiber diameter of $\mathrm{HP} \beta \mathrm{CD} / \mathrm{DMF}-\mathrm{NF}$, that cause stiffing effect to $\mathrm{CD} N \mathrm{NF}$, conversely decreasing at the elongation ratio. In the case of $\mathrm{HP} \gamma \mathrm{CD} /$ water-NF, there is sharp-cut decrease at the mechanical properties (Table S1) and this might be originated from the less integrated and compact nature of HP $\gamma$ CD NF compared to $\mathrm{HP} \beta \mathrm{CD}$ NF which can be also detected visually. These obtained results for CD NF are close to values of PVA NF reported in the literature (Peresin et al., 2010), in addition CD nanowebs have foldable and flexible feature that will not create trouble during their incorporation in a filter module.

Here, we have investigated the surface area of CD NF (HP $\beta C D$ and $\mathrm{HP} \gamma \mathrm{CD}$ ) and their as-received powder form by BET analysis (Table 1). The multipoint BET surface area for powder form of $\mathrm{HP} \beta \mathrm{CD}$ and $\mathrm{HP} \gamma \mathrm{CD}$ were calculated as $1.88 \mathrm{~m}^{2} / \mathrm{g}$ and $2.21 \mathrm{~m}^{2} / \mathrm{g}$, respectively. The obtained values are compatible with the literature (a)

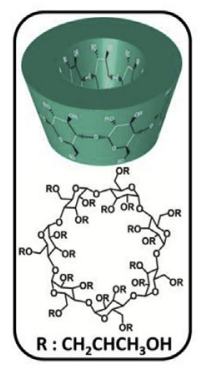

(b)

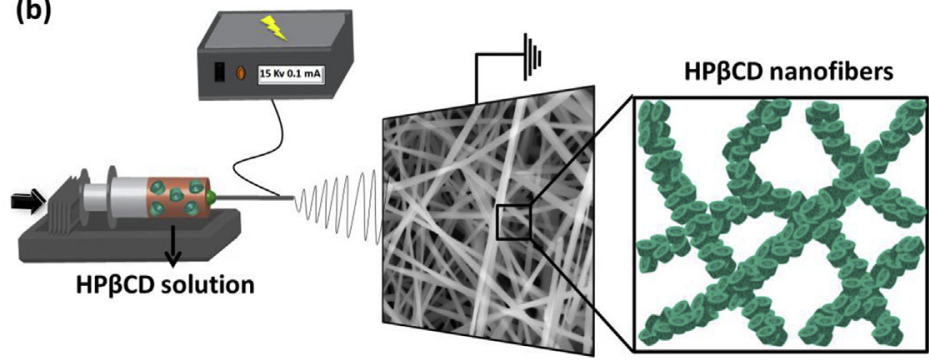

(c)

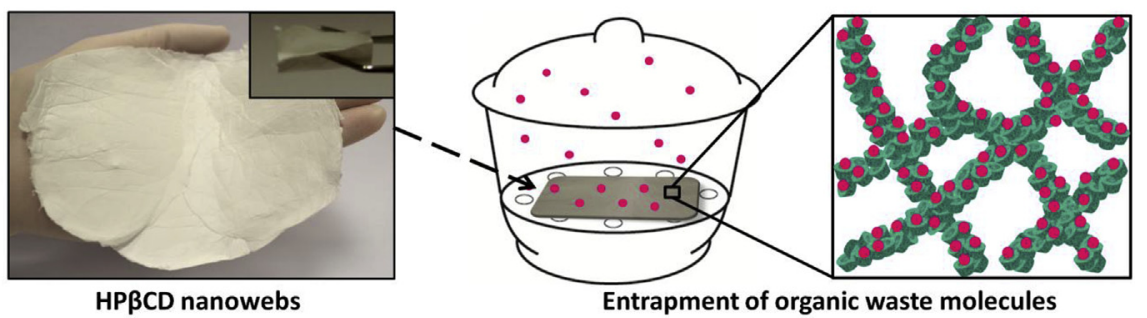

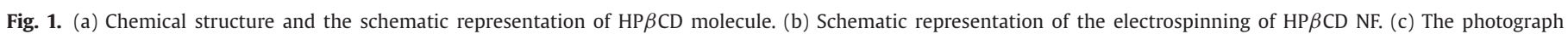
of $\mathrm{HP} \beta C D$ nanofibrous web and the schematic view of the molecular entrapment test. 

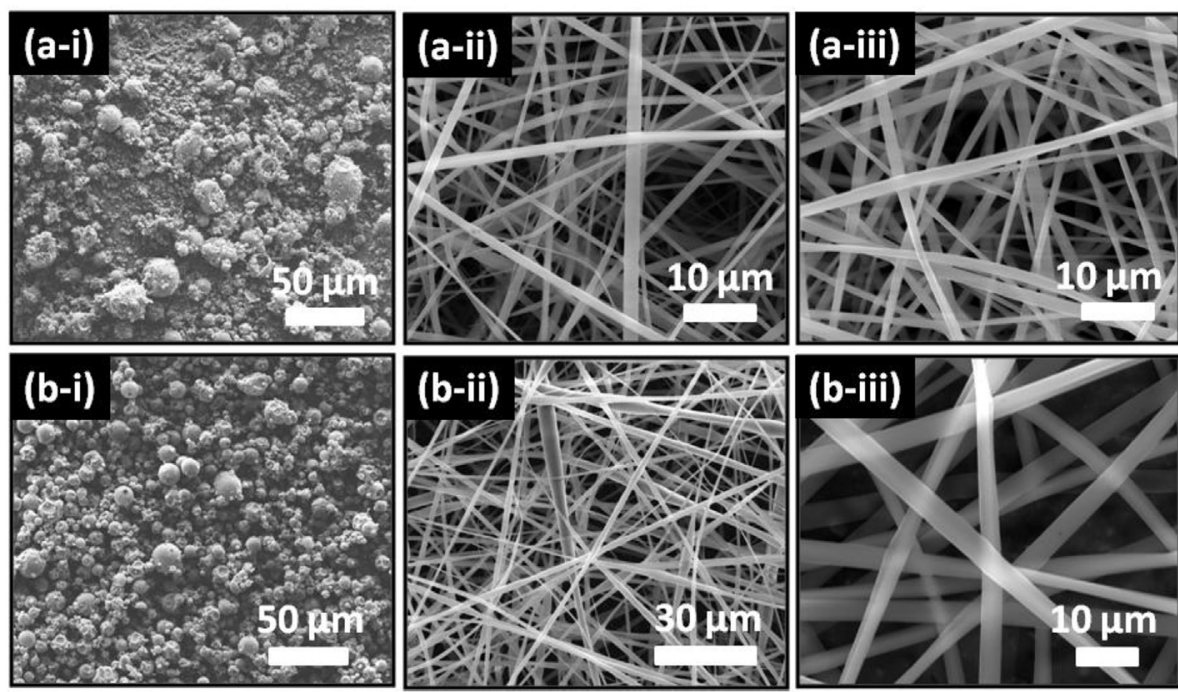

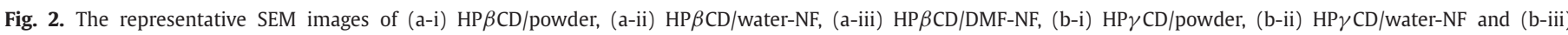
$\mathrm{HP} \gamma \mathrm{CD} / \mathrm{DMF}-\mathrm{NF}$

(Guo and Wilson, 2012; Ju et al., 2008). As it is seen from the SEM images, the CD powder consist of spherical beads in the average diameter of $22 \pm 17 \mu \mathrm{m}$ (3-71 $\mu \mathrm{m}$ range) and $7 \pm 4 \mu \mathrm{m}$ (1-21 $\mu \mathrm{m}$ range) for $\mathrm{HP} \beta C D$ and $\mathrm{HP} \gamma \mathrm{CD}$, respectively. So the higher surface area of $\mathrm{HP} \gamma \mathrm{CD}$ powder is probably originated from smaller bead dimension compared to $\mathrm{HP} \beta C D$ powder. As a result of electrospinning process, the surface areas were determined as $3.16 \mathrm{~m}^{2} / \mathrm{g}$ for $\mathrm{HP} \beta \mathrm{CD} /$ water-NF and $3.83 \mathrm{~m}^{2} / \mathrm{g}$ for $\mathrm{HP} \beta \mathrm{CD} / \mathrm{DMF}-\mathrm{NF}$. For $\mathrm{HP} \gamma \mathrm{CD} /$ water-NF and $\mathrm{HP} \gamma \mathrm{CD} / \mathrm{DMF}-\mathrm{NF}$, the surface areas were calculated as $2.27 \mathrm{~m}^{2} / \mathrm{g}$ and $3.48 \mathrm{~m}^{2} / \mathrm{g}$, respectively. So, it is evident that, electrospinning of $\mathrm{CD}$ into fiber form resulted in higher surface area when compared to powder form of $\mathrm{CD}$. In the case of $\mathrm{HP} \gamma \mathrm{CD}$, less difference was observed between the surface area of powder and NF form compared to $\mathrm{HP} \beta \mathrm{CD}$ based samples. In addition, there are slight changes at the surface areas of CD NF depending on the $\mathrm{CD}$ types and the electrospinning solvent types.

\subsection{VOCs entrapment capability of $C D N F$ and $C D$ powder}

Due to their relatively hydrophobic cavity, $C D$ are capable of forming inclusion complexes (IC) with variety of organic molecules and thus, $C D$ can be effective for the removal of hazardous molecules from the surroundings by inclusion complexation (Crini and Morcellet, 2002; Olah et al., 1988; Landy et al., 2012; MorinCrini and Crini, 2013; Schofield et al., 2012). In our previous studies, we have demonstrated that $\mathrm{CD}$ functionalized polymeric NF can be potentially used as molecular filters for the air and water filtration by removing organic molecules from the required environment (Kayaci et al., 2013; Kayaci and Uyar, 2014; Uyar et al., 2009, 2010a, 2010b). The integration of polymeric NF with CD, facilitated the entrapment property of nanofibrous webs owing to the complexation capability of $\mathrm{CD}$ molecules located on the fiber surface (Kayaci et al., 2013; Kayaci and Uyar, 2014; Uyar et al., 2009, 2010a, 2010b). Furthermore, in our very recent study, we eliminated the polymer matrix and we have shown that the polymer-free $\gamma$-CD NF can also efficiently encapsulate aniline and toluene vapor from the environment depending on the inclusion complexation so these nanofibrous webs have great potential to be used as a molecular filter (Celebioglu and Uyar, 2013b). The molecular filtration capability of $\mathrm{HP} \beta \mathrm{CD} \mathrm{NF}$ and $\mathrm{HP} \gamma \mathrm{CD}$ NF was investigated by using aniline and benzene as model VOCs which are known to form IC with CD (Hoshino and Imamura, 1981; Misawa et al., 2005; Uyar et al., 2006). We have also investigated the morphological stability of these CD NF by using SEM and the results confirmed that CD NF kept their fiber structure during the entrapment test (Fig. S2).

${ }^{1} \mathrm{H}-\mathrm{NMR}$ study was performed to determine the entrapped amount of VOCs by calculating the molar ratios of organic molecules (aniline and benzene) to $\mathrm{CD}(\mathrm{HP} \beta \mathrm{CD}$ and $\mathrm{HP} \gamma \mathrm{CD})$. Table 2 summarizes the average results which were obtained by integrating the peak ratio of the characteristic chemical shifts $(\delta)$ corresponding to VOCs and CD (Fig. 3). For aniline entrapment, it was observed that the molar ratio of aniline respect to $\mathrm{HP} \beta \mathrm{CD}$ (aniline:CD) is higher for $\mathrm{HP} \beta \mathrm{CD} / \mathrm{DMF}-\mathrm{NF}$ (1.38:1) compared to $\mathrm{HP} \beta \mathrm{CD} /$ water-NF $(0.68: 1)$ and it is at the lowest value for $\operatorname{HP} \beta C D /$ powder $(0.32: 1)$. The same trend was also obtained for $\mathrm{HP} \gamma \mathrm{CD}$ samples and the entrapped amount of aniline was calculated in the order of $\mathrm{HP} \gamma \mathrm{CD} / \mathrm{DMF}-\mathrm{NF}(0.25: 1)>\mathrm{HP} \gamma \mathrm{CD} /$ water$\mathrm{NF}(0.15: 1)>\mathrm{HP} \gamma \mathrm{CD} /$ powder $(0.09: 1)$. As evident from our results, $\mathrm{HP} \beta \mathrm{CD}$ based samples encapsulated more amount of aniline

Table 1

The characteristics of $\mathrm{CD}$ solutions, average fiber diameter, fiber diameter range and surface area of $\mathrm{CD}$ NF and $\mathrm{CD}$ powder

\begin{tabular}{|c|c|c|c|c|}
\hline Sample & Solvent & $\% \mathrm{CD}(\mathrm{w} / \mathrm{v})^{\mathrm{a}}$ & Average fiber diameter (nm) (fiber diameter range(nm)) & Surface area $\left(\mathrm{m}^{2} / \mathrm{g}\right)$ \\
\hline $\mathrm{HP} \beta \mathrm{CD} /$ powder & - & - & - & 1.88 \\
\hline $\mathrm{HP} \beta \mathrm{CD} /$ water-NF & water & 160 & $745 \pm 370 \mathrm{~nm}(250-1780)$ & 3.16 \\
\hline $\mathrm{HP} \beta \mathrm{CD} / \mathrm{DMF}-\mathrm{NF}$ & DMF & 120 & $1125 \pm 360 \mathrm{~nm}(400-1800)$ & 3.83 \\
\hline $\mathrm{HP} \gamma \mathrm{CD} /$ powder & - & - & - & 2.21 \\
\hline $\mathrm{HP} \gamma \mathrm{CD} /$ water-NF & water & 160 & $1165 \pm 455 \mathrm{~nm}(330-3750)$ & 2.27 \\
\hline $\mathrm{HP} \gamma \mathrm{CD} / \mathrm{DMF}-\mathrm{NF}$ & DMF & 125 & $2740 \pm 725 \mathrm{~nm}(1030-6500)$ & 3.48 \\
\hline
\end{tabular}

\footnotetext{
a With respect to solvent.
} 
Table 2

The molar ratio values of VOC:CD calculated from ${ }^{1} \mathrm{H}-\mathrm{NMR}$ and HPLC measurements (n:3, std dev: \pm 0.00 ). (The approximate entrapped VOC amounts calculated from the ${ }^{1} \mathrm{H}-\mathrm{NMR}$ in terms of $\mathrm{mg} / \mathrm{g}$.)

\begin{tabular}{lllll}
\hline & VOC:CD & CD/powder & CD/water-NF & CD/DMF-NF \\
\hline${ }^{1} \mathrm{H}-\mathrm{NMR}$ & Aniline: $\mathrm{HP} \beta \mathrm{CD}$ & $0.32: 1(20 / 1)$ & $0.68: 1(50 / 1)$ & $1.38: 1(100 / 1)$ \\
& Aniline: $\mathrm{HP} \gamma \mathrm{CD}$ & $0.09: 1(5 / 1)$ & $0.15: 1(9 / 1)$ & $0.25: 1(15 / 1)$ \\
& Benzene:HP $\beta$ CD & $0.10: 1(6 / 1)$ & $0.18: 1(11 / 1)$ & $0.38: 1(22 / 1)$ \\
\multirow{4}{*}{ HPLC } & Benzene: $\mathrm{HP} \gamma \mathrm{CD}$ & $0.02: 1(1 / 1)$ & $0.03: 1(1.5 / 1)$ & $0.06: 1(3 / 1)$ \\
& Aniline: $\mathrm{HP} \beta \mathrm{CD}$ & $0.40: 1$ & $0.97: 1$ & $1.67: 1$ \\
& Aniline: $\mathrm{HP} \gamma \mathrm{CD}$ & $0.14: 1$ & $0.21: 1$ & $0.32: 1$ \\
& Benzene:HP $\beta$ CD & $0.08: 1$ & $0.28: 1$ & $0.44: 1$ \\
& Benzene: $\mathrm{HP} \gamma \mathrm{CD}$ & $0.02: 1$ & $0.03: 1$ & $0.06: 1$ \\
\hline
\end{tabular}

compared to $\mathrm{HP} \gamma \mathrm{CD}$ based samples (Table 2). The possible reason would be bigger cavity size of $\mathrm{HP} \gamma \mathrm{CD}$ which leads to less stable interaction during the inclusion complexation, hence, less amount of aniline was possibly preserved in the $\mathrm{HP} \gamma \mathrm{CD}$ due to size mismatch between HP $\gamma$ CD cavity and aniline molecule. In the case of benzene entrapment, the molar ratios significantly decreased, that indicates the lower entrapping efficiency of samples compared to aniline exposed samples (Table 2). This situation can be originated from the weaker specific local interaction between benzene and $\mathrm{CD}$ molecules. For $\mathrm{HP} \beta \mathrm{CD}$ based samples, the entrapping effi-
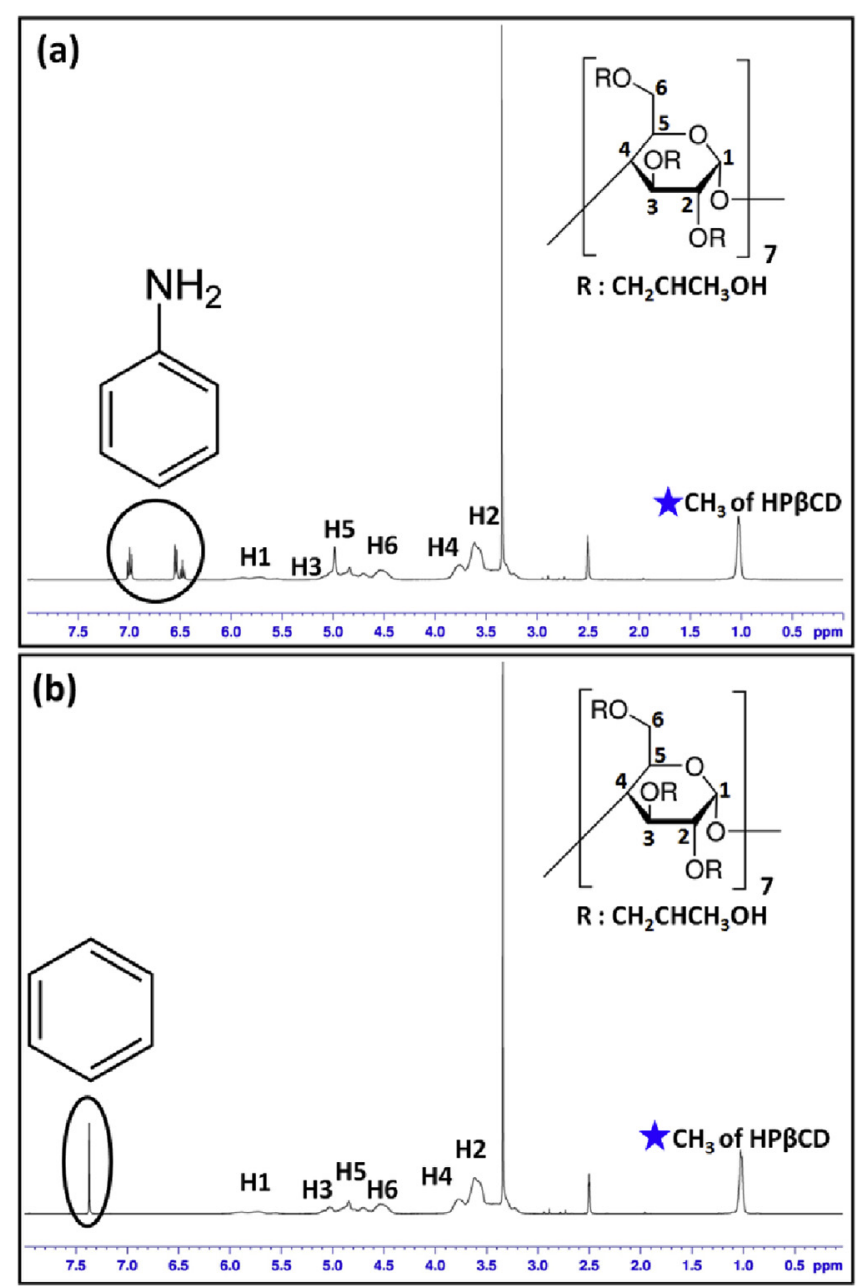

Fig. 3. Representative ${ }^{1} \mathrm{H}-\mathrm{NMR}$ spectra of (a) aniline and (b) benzene exposed $\mathrm{HP} \beta \mathrm{CD} / \mathrm{DMF}-\mathrm{NF}$ which were taken in $d 6$-DMSO. The assignments written as H1-H6 correspond to characteristic chemical shifts $(\delta)$ of protons next to $\mathrm{C}$ atom numbered in $\mathrm{CD}$ molecules. ciency is in the order of $\mathrm{HP} \beta \mathrm{CD} / \mathrm{DMF}-\mathrm{NF}(0.38: 1)>\mathrm{HP} \beta \mathrm{CD} /$ water$\mathrm{NF}(0.18: 1)>\mathrm{HP} \beta \mathrm{CD} /$ powder $(0.10: 1)$, having a similar trend with aniline treatment. For $\mathrm{HP} \gamma \mathrm{CD}$ based samples, distinctive reduction was observed for the entrapped amount of benzene which was possibly originated from the improper size match between $\mathrm{HP} \gamma \mathrm{CD}$ cavity and benzene molecule. After all, similar to aniline test, $\mathrm{HP} \gamma \mathrm{CD} / \mathrm{DMF}-\mathrm{NF}(0.06: 1)$ entrapped higher amount of benzene from the environment compared to $\mathrm{HP} \gamma \mathrm{CD} /$ water-NF $(0.03: 1)$, and $\mathrm{HP} \gamma \mathrm{CD} /$ powder $(0.02: 1)$ displayed the lowest entrapment efficiency among other samples. To evaluate obtained results more practically, we have also calculated molar ratio values in terms of $\mathrm{mg} / \mathrm{g}(\mathrm{VOCs} / \mathrm{CD})$ and this provided better visualization for the VOC entrapment capacity of $1 \mathrm{~g} C D$ samples (NF or powder) from the environment. The all above pontificated reasons for the entrapment differentiation between samples were proved by the correlated modeling study in terms of complexation energy, which will be detailed in the next part. In short, CD NF have shown higher amount of VOCs entrapment when compared to their powder form and this is possibly due to the higher surface area. Yet, high surface area may not be the only factor for the enhanced entrapment efficiency. For instance, CD NF produced from DMF solvent system have shown higher amount of VOCs entrapment and this may be originated from the higher accessibility and availability of CD cavity to entrap VOCs from the environment.

The entrapment performance of CD NF was also tested by HPLC measurements. After exposure to aniline and benzene vapor, NF were dissolved in water and water/acetonitrile $(\mathrm{ACN})$, respectively to perform chromatographic measurements. The HPLC analyses were performed three times for each of the sample. Fig. 4 summarized the HPLC results which were taken for water and DMF based samples of $\mathrm{HP} \beta \mathrm{CD} \mathrm{NF}$ and $\mathrm{HP} \gamma \mathrm{CD} \mathrm{NF}$, and as well their powder forms. The results were calculated in terms of ppm by adapting to calibration curve which were plotted according to different concentration of aniline and benzene. The HPLC results, given in terms of concentration (Fig. 4), were also calculated as molar ratios (VOCs:CD). Table 2 depicts the molar ratio values which were converted from the HPLC results. When HPLC results were compared with ${ }^{1} \mathrm{H}-\mathrm{NMR}$, it was found that, the molar ratios are not exactly

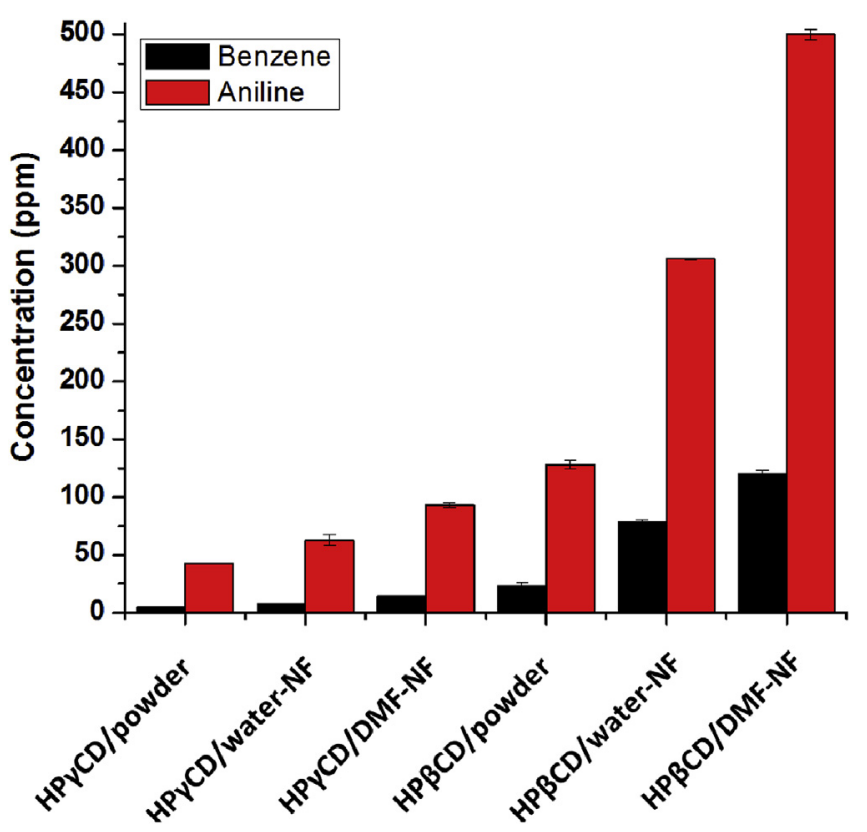

Fig. 4. The summary of HPLC results showing the amount of aniline and benzene entrapped by $\mathrm{HP} \beta \mathrm{CD} /$ powder, $\mathrm{HP} \beta \mathrm{CD} /$ water-NF, $\mathrm{HP} \beta \mathrm{CD} / \mathrm{DMF}-\mathrm{NF}, \mathrm{HP} \gamma \mathrm{CD} /$ powder, $\mathrm{HP} \gamma \mathrm{CD} /$ water-NF and $\mathrm{HP} \gamma \mathrm{CD} / \mathrm{DMF}-\mathrm{NF}$. 
same with each other, however, the values are close to each other and they follow a similar trend. We have noticed from the graph that, $\mathrm{HP} \beta C D \mathrm{NF}$ and powder can encapsulate higher amount of VOCs from the environment compared to HP $\gamma \mathrm{CD}$ NF and powder. This was probably originated from the bigger cavity of $\mathrm{HP} \gamma \mathrm{CD}$, that is, size mismatch and weaker interaction between $\mathrm{HP} \gamma \mathrm{CD}$ cavity and VOCs (aniline and benzene) for the encapsulation. When the $\mathrm{HP} \beta C D$ and $\mathrm{HP} \gamma \mathrm{CD}$ based samples were compared, the entrapped amount of aniline and benzene were on the order of DMF > water > powder for both $\mathrm{CD}$ types which was also consistent with the ${ }^{1} \mathrm{H}-\mathrm{NMR}$ measurements. Moreover, aniline molecules can be more efficiently removed from the environment compared to benzene molecules by CD NF and their powder.

In order to confirm the complexation between $\mathrm{CD}$ molecules and VOCs, TGA was performed for CD NF and their powder after they were exposed to aniline and benzene vapor. When the volatile organic molecules are encapsulated in CD cavities, the thermal decomposition/evaporation of the guest molecules shifts to higher temperature owing to the interaction between $\mathrm{CD}$ cavity. The TGA thermograms of all samples and pure aniline were shown in Fig. S3. The main weight loss that is observed at about $350{ }^{\circ} \mathrm{C}$ belongs to the main thermal degradation of $\mathrm{CD}$ molecules and the initial weight loss for untreated samples correspond to water content in $\mathrm{CD}$ samples. In addition, it was observed that the pristine CD NF produced form DMF have shown slight weight loss till
$180{ }^{\circ} \mathrm{C}$ possible due to the remaining solvent residue after electrospinning process. For aniline, the inception point of thermal evaporation is interfered with water, so it was evaluated according to the temperature at which the evaporation came to an end (Fig. S3ab). While the evaporation of pure aniline occurs below $100{ }^{\circ} \mathrm{C}$, it evolved close to $200{ }^{\circ} \mathrm{C}$ for the $\mathrm{CD} N \mathrm{NF}$ and powder exposed to aniline vapor. In addition, for both $\mathrm{HP} \beta \mathrm{CD}$ and $\mathrm{HP} \gamma \mathrm{CD}$ samples, the \% weight loss was increased in the order of powder $<$ water $<$ DMF which was consistent with quantitative results of ${ }^{1} \mathrm{H}-\mathrm{NMR}$ and HPLC measurements. In the case of pure benzene, we could not able to record the TGA data due to their extremely high volatile nature. The expected \% weight loss was also observed for benzene exposed samples in the order of powder $<$ water $<$ DMF. However, in TGA thermograms of benzene exposed $\mathrm{HP} \beta \mathrm{CD}$ and $\mathrm{HP} \gamma \mathrm{CD}$ powder (Fig. S3c(i)-d(i)), the initial weight loss are observed at lower level compared to pristine samples. As it was mentioned above, the initial weight loss step of untreated CD samples is originated due to water content present in the $C D$ samples. Once the benzene was entrapped, the water molecules were replaced with benzene molecules, but the entrapped benzene amount was lower than the water content in powder CD samples. After all, we have determined that, the benzene exposed samples showed identical trend, and the evaporation of benzene was observed up to $150{ }^{\circ} \mathrm{C}$ (Fig. S3c-d). It is clear that, the thermal decomposition/evaporation of aniline and benzene occurred at much higher temperature when
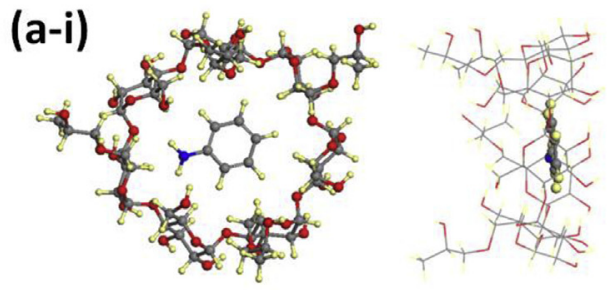

(a-ii)
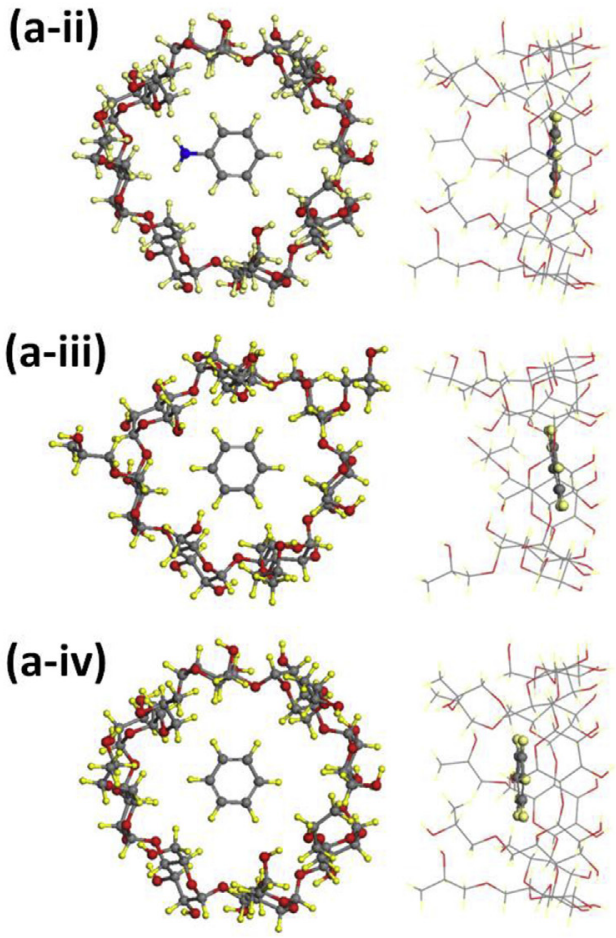
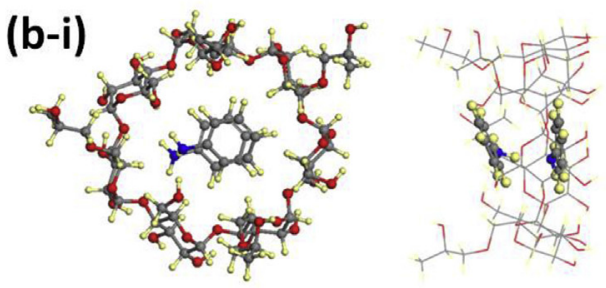

(b-ii)
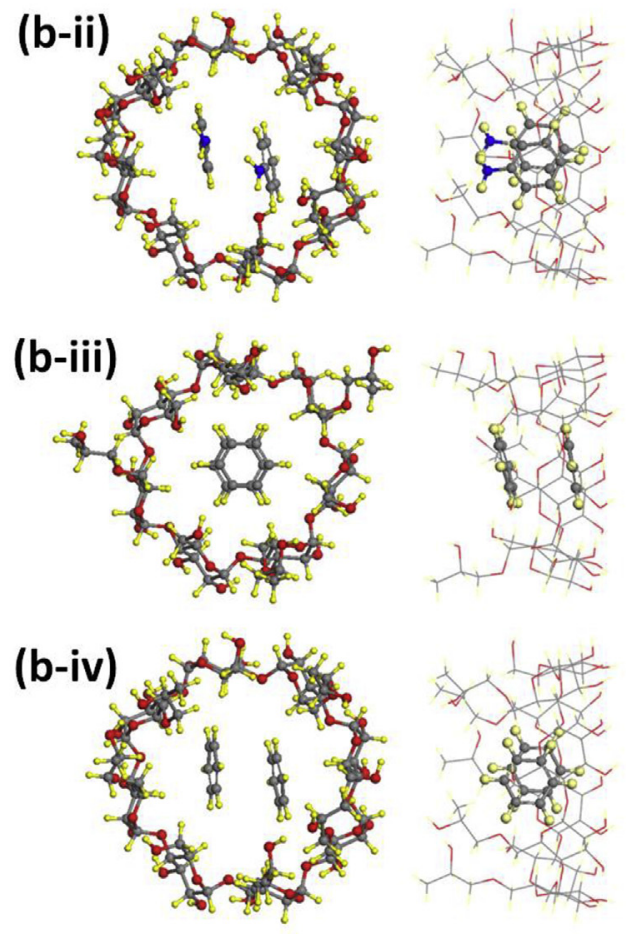

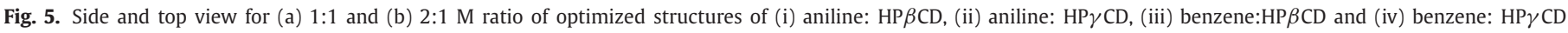

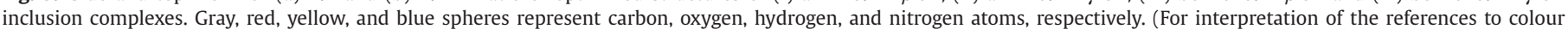
in this figure legend, the reader is referred to the web version of this article.) 
compared to their pure form, suggesting that aniline and benzene molecules were encapsulated in CD cavity by inclusion complexation.

\subsection{Molecular modeling of VOCs:CD}

The stability of complexation between chemically modified CD molecules and VOCs is further examined by using first-principles modeling techniques. In our system, nanofibers compose of many aggregated $\mathrm{CD}$ molecules that are weakly interacting with each other, so accordingly considering single isolated CD is fairly good model to study complexation. In order to form a complex a single VOC (aniline or benzene) is introduced into $\mathrm{HP} \beta C D$ and $\mathrm{HP} \gamma \mathrm{CD}$ at various positions considering all possible orientations. The calculations are then repeated with two VOCs corresponding to 2:1 (VOC:CD) molar ratio. For each case the whole system is relaxed without imposing any constraints. The configurations yielding the lowest energy are shown in Fig. 5. The complexation energy ( $E_{\text {comp }}$ ) is calculated by

$\mathrm{E}_{\mathrm{comp}}=\mathrm{E}_{\mathrm{CD}}+n * \mathrm{E}_{\mathrm{VOC}}-\mathrm{E}_{\mathrm{IC}}$

where $E_{C D}, E_{V O C}$, and $E_{I C}$ are the total energy of chemically modified $\mathrm{CD}$ (HP $\beta \mathrm{CD}$ or $\mathrm{HP} \gamma \mathrm{CD}$ ), VOC (aniline or benzene) and IC (aniline: $\mathrm{HP} \beta \mathrm{CD}$, benzene: $\mathrm{HP} \beta \mathrm{CD}$, aniline: $\mathrm{HP} \gamma \mathrm{CD}$, or benzene: $\mathrm{HP} \gamma \mathrm{CD}$ ), respectively in vacuum and $n$ is the number of VOCs (1 or 2 depending the molar ratio). $\mathrm{E}_{\text {comp }}$ is calculated as 35.05 and $32.49 \mathrm{kcal} / \mathrm{mol}$ for open and close HP arms, respectively. When HP arms get closer narrowing the rim, $\mathrm{E}_{\text {comp }}$ slightly reduces. Our results support the formation of stable IC of VOCs and HP $\beta C D$ with 1:1 M ratio. The results are summarized in Table S2.

Our results indicate that the total energy reduces upon introducing guest molecules (aniline or benzene) which confirm the complexation between VOCs and CDs. While VOCs prefer horizontal orientation inside the cavity of $C D$ for $1: 1 \mathrm{M}$ ratio, vertical orientation can be observed for 2:1 M ratio. When CDs are considered, $\mathrm{E}_{\text {comp }}$ is higher when $\mathrm{HP} \beta \mathrm{CD}$ is the host molecule, indicating a better entrapping efficiency compared to $\mathrm{HP} \gamma \mathrm{CD}$. In addition, the highest $\mathrm{E}_{\text {comp }}$ is obtained for aniline-HP $\beta C D$ IC which is also in parallel with the experimental data in reported in Table 2. During the formation of CD IC, van der Waals interactions, hydrogen bonding, release of high energy water and decrease in the strain energy in the CD cavity are the general driving forces (Uyar et al., 2006). Otherwise, hydrophobic interactions are the main relation between aromatic ring and CD cavity. Besides, in the case of aniline and $\mathrm{CD}$ complexation, the hydrogen bonding between the amine group of aniline and hydroxyl group of $\mathrm{CD}$ is also possible, so the extra contribution of this hydrogen bond might explain the higher complexation energy of aniline based interactions compared to benzene based ones (Table S2).

\section{Conclusions}

The HP $\beta$ CD NF and HP $\gamma$ CD NF were successfully obtained from DMF and water solvent system via electrospinning. The molecular entrapment performance of $\mathrm{CD} N \mathrm{NF}$ and their powder forms were investigated by exposing them to VOCs; aniline and benzene vapor. We have observed that, CD NF can entrap higher amount of VOCs from the surroundings compared to their powder forms, in addition, the entrapment efficiency was highly dependent on the CD type (HP $\beta C D$ and $\mathrm{HP} \gamma \mathrm{CD}$ ) and VOCs type (aniline and benzene). Here, the differentiation between the complexation efficiency of samples was also evaluated and proved by the modeling study in terms of complexation energy. The BET analysis confirmed that, the NF have higher surface area compared to their powder forms. Therefore, the effective entrapment of VOCs by CD NF samples might be originated from the higher surface area of NF and the superior accessibility and availability of CD cavity to entrap VOCs. Furthermore, the mechanical integrity of CD NF was exhibited by DMA technique, supplemental to visual consideration. In this report, CD powder was transformed into more applicable nanofibrous form which can be readily used as filtering material for the entrapment of VOCs, especially during the storage and transfer part of the industrial process. In brief, electrospun CD NF would be very attractive for air filtration applications due to their highly porous structure and high surface area as well as their molecular entrapment capability of VOCs by inclusion complexation.

\section{Acknowledgments}

The Scientific and Technological Research Council of Turkey (TUBITAK, project \#213M185 and \#113Y348) is acknowledged for funding the research. T.U. thanks The Turkish Academy of Sciences - Outstanding Young Scientists Award Program (TUBA-GEBIP) for partial funding. A. C. thank TUBITAK-BIDEB and TUBITAK (project \#113Y348) for $\mathrm{PhD}$ scholarship and postdoctoral fellowship, respectively.

\section{Appendix A. Supplementary data}

Supplementary data related to this article can be found at http: //dx.doi.org/10.1016/j.chemosphere.2015.09.029.

\section{References}

Allen, F.H., 2002. The Cambridge Structural Database: a quarter of a million crystal structures and rising. Acta Crystallogr. Sect. B Struct. Sci. 58, 380-388.

Aluigi, A., Rombaldoni, F., Tonettib, C., Jannokec, L., 2014. Study of Methylene Blue adsorption on keratin nanofibrous membranes. J. Hazard. Mater. 268, 156-165.

Aussawasathien, D., Teerawattananon, C., Vongachariya, A., 2008. Separation of micron to sub-micron particles from water: electrospun nylon-6 nanofibrous membranes as pre-filters. J. Membr. Sci. 315, 11-19.

Bai, Y., Huang, Z.-H., Kang, F., 2013a. Synthesis of reduced graphene oxide/phenolic resin-based carbon composite ultrafine fibers and their adsorption performance for volatile organic compounds and water. J. Mater. Chem. A 1, 9536-9543.

Bai, Y., Huang, Z.-H., Kang, F., Wang, M.-X., 2013b. Adsorption of benzene and ethanol on activated carbon nanofibers prepared by electrospinning. Adsorption $19,1035-1043$

Blach, P., Fourmentin, S., David, L., Cazier, F., Surpateanu, G., 2008. Cyclodextrins: a new efficient absorbent to treat waste gas streams. Chemosphere 70, 374-380.

Blöchl, P.E., 1994. Projector augmented-wave method. Phys. Rev. B 50, 17953.

Bradley, R.H., Rand, B., 1995. On the physical adsorption of vapors by microporous carbons. J. Colloid Interface Sci. 169, 168-176.

Bradley, R.H., Smith, M.W., Andreu, A., Falco, M., 2011. Surface studies of novel hydrophobic active carbons. Appl. Surf. Sci. 257, 2912-2919.

Celebioglu, A., Uyar, T., 2010. Cyclodextrin nanofibers by electrospinning. Chem. Comm. 46, 6903-6905.

Celebioglu, A., Uyar, T., 2012. Electrospinning of nanofibers from non-polymeric systems: polymer-free nanofibers from cyclodextrin derivatives. Nanoscale 4, 621631.

Celebioglu, A., Uyar, T., 2013a. Electrospinning of nanofibers from non-polymeric systems: electrospun nanofibers from native cyclodextrins. J. Colloid Interface Sci. 404, 1-7.

Celebioglu, A., Uyar, T., 2013b. Electrospun gamma-cyclodextrin ( $\gamma$-CD) nanofibers for the entrapment of volatile organic compounds. RSC Adv. 3, 22891-22895.

Crini, G., Morcellet, M., 2002. Synthesis and applications of adsorbents containing cyclodextrins. J. Sep. Sci. 25, 789-813.

De Crom, J., Claeys, S., Godayol, A., Alonso, M., Antico, E., Sanchez, J.M., 2010 Sorbent-packed needle microextraction trap for benzene, toluene, ethylbenzene, and xylenes determination in aqueous samples. J. Sep. Sci. 33, 2833-2840.

Esteve-Turrillas, F., Armenta, S., Garrigues, S., Pastor, A., de la Guardia, M., 2007. Headspace-mass spectrometry determination of benzene, toluene and the mixture of ethylbenzene and xylene isomers in soil samples using chemometrics. Anal. Chim. Acta 587, 89-96.

Favier, I.M., Baudelet, D., Fourmentin, S., 2011. VOC trapping by new crosslinked cyclodextrin polymers. J. Incl. Phenom. Macrocycl. Chem. 69, 433-437.

Flaherty, R.J., Nshime, B., DeLaMarre, M., DeJong, S., Scott, P., Lantz, A.W., 2013. Cyclodextrins as complexation and extraction agents for pesticides from contaminated soil. Chemosphere 91, 912-920.

Greiner, A., Wendorff, J.H., 2007. Electrospinning: a fascinating method for the preparation of ultrathin fibers. Angew. Chem. Int. Ed. 46, 5670-5703.

Grimme, S., 2006. Semiempirical GGA-type density functional constructed with a long-range dispersion correction. J. Comput. Chem. 27, 1787-1799.

Guo, R., Wilson, L.D., 2012. Preparation and sorption studies of microsphere copolymers containing $\beta$-cyclodextrin and poly (acrylic acid). J. Appl. Polym. Sci. 125, 1841-1854. 
Harada, A., Kobayashi, R., Takashima, Y., Hashidzume, A., Yamaguchi, H., 2011. Macroscopic self-assembly through molecular recognition. Nat. Chem. 3, 34-37.

Harata, K., 1987. The structure of the cyclodextrin complex. XX. Crystal structure of uncomplexed hydrated $\gamma$-cyclodextrin. Bull. Chem. Soc. Jpn. 60, 2763-2767.

Hedges, A.R., 1998. Industrial applications of cyclodextrins. Chem. Rev. 98, 20352044.

Hohenberg, P., Kohn, W., 1964. Inhomogeneous electron gas. Phys. Rev. 136, B864.

Hoshino, M., Imamura, M., 1981. Fluorescence enhancement of benzene derivatives by forming inclusion complexes with. beta.-cyclodextrin in aqueous solutions. J. Phys. Chem. 85, 1820-1823.

Irusta, S., Pina, M.P., Menendez, M., Santamaria, J., 1998. Development and application of perovskite-based catalytic membrane reactors. J. Catal. 179, 400-412.

Ju, J.-F., Syu, M.-J., Teng, H.-S., Chou, S.-K., Chang, Y.-S., 2008. Preparation and identification of $\beta$-cyclodextrin polymer thin film for quartz crystal microbalance sensing of benzene, toluene, and p-xylene. Sens. Actuators B 132, 319-326.

Katepalli, H., Bikshapathi, M., Sharma, C.S., Verma, N., Sharma, A., 2011. Synthesis of hierarchical fabrics by electrospinning of PAN nanofibers on activated carbon microfibers for environmental remediation applications. Chem. Eng. J. 171, 1194-1200.

Kayaci, F., Aytac, Z., Uyar, T., 2013. Surface modification of electrospun polyester nanofibers with cyclodextrin polymer for the removal of phenanthrene from aqueous solution. J. Hazard. Mater. 261, 286-294.

Kayaci, F., Uyar, T., 2014. Electrospun polyester/cyclodextrin nanofibers for entrapment of volatile organic compounds. Polym. Eng. Sci. 54, 2970-2978.

Kim, H.J., Pant, H.R., Choi, N.J., Kim, C.S., 2013. Composite electrospun fly ash/polyurethane fibers for absorption of volatile organic compounds from air. Chem. Eng. J. 230, 244-250.

Kohn, W., Sham, L.J., 1965. Self-consistent equations including exchange and correlation effects. Phys. Rev. 140, A1133.

Kresse, G., Furthmüller, J., 1996a. Efficiency of ab-initio total energy calculations for metals and semiconductors using a plane-wave basis set. Comput. Mater. Sci. 6, 15-50.

Kresse, G., Furthmüller, J., 1996b. Efficient iterative schemes for ab initio totalenergy calculations using a plane-wave basis set. Phys. Rev. B 54, 11169.

Landy, D., Mallard, I., Ponchel, A., Monflier, E., Fourmentin, S., 2012. Remediation technologies using cyclodextrins: an overview. Environ. Chem. Lett. 10, 225-237.

Lee, K.J., Shiratori, N., Lee, G.H., Miyawaki, J., Mochida, I., Yoon, S.-H., Jang, J., 2010. Activated carbon nanofiber produced from electrospun polyacrylonitrile nanofiber as a highly efficient formaldehyde adsorbent. Carbon 48, 4248-4255.

Li, D., Xia, Y., 2004. Electrospinning of nanofibers: reinventing the wheel? Adv. Mater. 16, 1151-1170.

Lindner, K., Saenger, W., 1982. Crystal and molecular structure of cycloheptaamylose dodecahydrate. Carbohydr. Res. 99, 103-115.

Majumbar, S., Bhaumik, D., Sirkar, K.K., Simes, G., 2001. A pilot-scale demonstration of a membrane-based absorption-stripping process for removal and recovery of volatile organic compounds. Environ. Prog. 20, 27-35.

Mauri-Aucejo, R., Liobat-Estel, M., Egea, M.G., Guillem, C., Amoros, P., 2012. Samplers for VOCs in air based on cyclodextrin-silica hybrid microporous solid phases. Analyst 137, 1275-1283.

Meniconi, M.F.G., Parris, R., Thomas, C.L.P., 2003. Fast volatile organic compound recovery from soil standards for analysis by thermal desorption gas chromatography. Analyst 128, 1232-1237.

Misawa, K.S., Saito, Y., Aki, K.H., Taguchi, H., Ogawa, N., Ueda, H., 2005. Stability constants for 1: 1 complexes formed between2-hydroxypropyl- $\beta$-cyclodextrin with an average substitution degree of 4.4 and benzene and alkylbenzenes as guests by modified static head-space gas chromatography method. J. Incl. Phenom. Macrocycl. Chem. 53, 237-240.

Morin-Crini, N., Crini, G., 2013. Environmental applications of water-insoluble $\beta$ cyclodextrin-epichlorohydrin polymers. Prog. Polym. Sci. 38, 344-368.
Olah, J., Cserhati, T., Szejtli, J., 1988. $\beta$-Cyclodextrin enhanced biological detoxification of industrial wastewaters. Water Res. 22, 1345-1351.

Pant, H.R., Kim, H.J., Joshia, M.K., Panta, B., Parka, C.H., Kima, J.I., Huid, K.S. Kima, C.S., 2014. One-step fabrication of multifunctional composite polyurethane spider-web-like nanofibrous membrane for water purification. J. Hazard. Mater. 264, 25-33.

Pant, H.R., Pant, B., Pokharel, P., Kimd, H.J., Tijing, L.D., Parka, C.H., Leec, D.S., Kima, H.Y., Kim, C.S., 2013. Photocatalytic $\mathrm{TiO}_{2}-\mathrm{RGO} /$ nylon-6 spider-wave-like nano-nets via electrospinning and hydrothermal treatment. J. Membr. Sci. 429, 225-234.

Perdew, J.P., Chevary, J.A., Vosko, S.H., Jackson, K.A., Pederson, M.R., Singh, D.J. Fiolhais, C., 1992. Atoms, molecules, solids, and surfaces: applications of the generalized gradient approximation for exchange and correlation. Phys. Rev. B 46, 6671-6687.

Peresin, M.S., Habibi, Y., Vesterinen, A.-H., Rojas, O.J., Pawlak, J.J., Seppala, J.V., 2010 Effect of moisture on electrospun nanofiber composites of poly (vinyl alcohol) and cellulose nanocrystals. Biomacromolecules 11, 2471-2477.

Ramakrishna, S., Fujihara, K., Teo, W., Lim, T., Ma, Z., 2005. An Introduction to Electrospinning and Nanofibers. World Scientific.

Ramakrishna, S., Fujihara, K., Teo, W.E., Yong, T., Ma, Z., Ramaseshan, R., 2006. Electrospun nanofibers: solving global issues. Mater. Today 9, 40-50.

Schofield, W.C.E., Bain, C.D., Badyal, J.P.S., 2012. Cyclodextrin-functionalized hierarchical porous architectures for high-throughput capture and release of organic pollutants from wastewater. Chem. Mater. 24, 1645-1653.

Scholten, E., Bromberg, L., Rutledge, G.C., Hatton, T.A., 2011. Electrospun polyurethane fibers for absorption of volatile organic compounds from air. ACS Appl. Mater. Interfaces 3, 3902-3909.

Shao, D., Sheng, G., Chen, C., Wanga, X., Nagatsu, M., 2010. Removal of polychlorinated biphenyls from aqueous solutions using $\beta$-cyclodextrin grafted multiwalled carbon nanotubes. Chemosphere 79, 679-685.

Szejtli, J., 1998. Introduction and general overview of cyclodextrin chemistry. Chem. Rev. 98, 1743-1754.

Uyar, T., Besenbacher, F., 2008. Electrospinning of uniform polystyrene fibers: the effect of solvent conductivity. Polymer 49, 5336-5343.

Uyar, T., Havelund, R., Hacaloglu, J., Besenbacher, F., Kingshott, P., 2010a. Functional electrospun polystyrene nanofibers incorporating $\alpha-, \beta-$, and $\gamma$-cyclodextrins: comparison of molecular filter performance. ACS Nano 4, 5121-5130.

Uyar, T., Havelund, R., Nur, Y., Balan, A., Hacaloglu, J., Toppare, L., Besenbacher, F. Kingshott, P., 2010b. Cyclodextrin functionalized poly (methyl methacrylate)(PMMA) electrospun nanofibers for organic vapors waste treatment J. Membr. Sci. 365, 409-417.

Uyar, T., Havelund, R., Nur, Y., Hacaloglu, J., Besenbacher, F., Kingshott, P., 2009. Molecular filters based on cyclodextrin functionalized electrospun fibers. J. Membr. Sci. 332, 129-137.

Uyar, T., Hunt, M.A., Gracz, H.S., Tonelli, A.E., 2006. Crystalline cyclodextrin inclusion compounds formed with aromatic guests: guest-dependent stoichiometries and hydration-sensitive crystal structures. Cryst. Growth Des. 6, 1113-1119.

Vermisoglou, E., Georgakilas, V., Kouvelos, E., Pilatos, G., Viras, K., Romanos, G., Kanellopoulos, N.K., 2007. Sorption properties of modified single-walled carbon nanotubes. Microporous Mesoporous Mater. 99, 98-105.

Wang, J., Pan, K., He, Q., Cao, B., 2013. Polyacrylonitrile/polypyrrole core/shell nanofiber mat for the removal of hexavalent chromium from aqueous solution. J. Hazard. Mater. 244, 121-129.

Wendorff, J.H., Agarwal, S., Greiner, A., 2012. Electrospinning: Materials, Processing, and Applications. John Wiley \& Sons.

Xie, J., Li, X., Xia, Y., 2008. Putting electrospun nanofibers to work for biomedical research. Macromol. Rapid Commun. 29, 1775-1792.

Yoon, K., Hsiao, B., Chu, B., 2008. Functional nanofibers for environmental applications. J. Mater. Chem. 18, 5326-5334. 